\title{
Physical and Abstract Elements that Support Cooperation between Team Members During Systems Development
}

\author{
A. C. Leonard \\ University of Pretoria, South Africa
}

aleonard@hakuna.up.ac.za

\begin{abstract}
This paper addresses the problem of cooperation between team members by describing two dimensions of elements, namely the physical and abstract dimension, to be focused on by all participants of a systems development team. A conceptual framework is introduced which describes these two dimensions. In the second part of the paper the nature of and theory behind sound relationships between team members of software projects are examined. The conceptual framework shows the position and relationship of each element during systems development process. This conceptual framework helps managers to understand the complexity of such relationships and it gives a structured view of the role of the elements of the two dimensions during systems development.
\end{abstract}

Keywords: $\quad$ relationships, team work, soft issues, cooperation, systems development

\section{Introduction}

The lack of knowledge in terms of which are the important elements to focus on in order to ensure cooperation between team members of systems development teams, has been an issue since the early days of systems development. In other words, it is argued that one key to improving software development is to make it easier for the team members of a software development project to work together. This perspective is supported by many other researchers (Boehm, 1981, 1987, DeMarco and Lister, 1988, DeMarco, 1995, Sawyer et al, 1997). This paper addresses this problem by describing some of the most important elements that should be focused on by all participants of a systems development team to ensure that they not only understand these elements, but that they know how to apply them to ensure mutual understanding and cooperation between team members.

Material published as part of this proceedings, either on-line or in print, is copyrighted by the author with permission granted to the publisher of Informing Science for this printing. Permission to make digital or paper copy of part or all of these works for personal or classroom use is granted without fee provided that the copies are not made or distributed for profit or commercial advantage AND that copies 1) bear this notice in full and 2) give the full citation on the first page. It is permissible to abstract these works so long as credit is given. To copy in all other cases or to republish or to post on a server or to redistribute to lists requires specific permission from the author.
If one believes that the understanding and applying of such elements could be regarded as a "team strategy", the work of Reich \& Benbasit (1999, referring to the work of Horovitz, 1984) supports the importance of understanding and applying such elements. Reich \& Benbasit point out that there are two dimensions to strategy creation: the intellectual dimension and the social dimension. Research into the intellectual dimension is more likely to concentrate on the contents of plans and on planning methodologies. Research into the social dimension is more likely to focus on the people involved in the creation of alignment. The social dimension of alignment is defined as "the state in which business and IT executives within an organizational unit understand and are committed to the business and IT mission, objectives, and plans". This "state" is of course just as important for participants of a software systems development team as it is for top management of the IT department and the business.

Another theoretical perspective supporting the concept of the social dimension is the social construction of reality. This view would suggest that, in addition to studying artifacts (such as plans and structures) to predict the presence or absence of alignment, one should investigate the contents of the players' minds: their beliefs, attitudes and understanding of these artifacts (Reich \& Benbasit, 1999). 


\section{Physical and Abstract Elements}

The paper focuses on the social dimension in terms of identifying the important elements and the role they play in team development and cooperation. The paper is based on research done in the area of how sound relationships between IT departments and end users should be constructed and managed. Research in this field has shown that relationships between IT professionals and their end users are intriguing and complex, and should be seen and managed as a multidimensional environment. The objectives of the research were, inter alia, to identify and describe the most important elements (hard and soft issues) which will enhance a supportive culture - "which will make it easier for developers to work together" (Sawyer et al, 1996). Furthermore the research was aimed at creating a better understanding of the social nature and characteristics of systems development teams while IT is performing its duty as service and support agent.

\section{Participants Of Software Systems Development Teams: Historical Foundations}

For many years the culture gap between IT departments and their end users has been characterized by unfortunate differences like distrust, scepticism and cynicism. This situation impacts negatively on the cooperation between participants of systems development teams and as such on their ability to produce service and support of high quality.

Historically the gap was caused mainly by the difference in management culture, as well as human behaviour problems on both sides. Umbaugh (1991) states in his argumentation of organizational imbalances that too often IT exists as an adjunct to the organization and not as an integral part of the whole. This situation unfortunately still exists today and contributes to the so-called culture gap between IT departments and their end users. Du Plooy (1995) explains this gap as follows:

“...the 'culture gap' should be understood as a gap of misunderstanding in the sense of two different organizational 'cultures' that, according to Grindley, coexist in most organizations. The two cultures under discussion here are the 'culture' of the IT profession and the 'culture' of the rest of the organization."

The culture on both the IT department and the business side is also an important obstacle in building mutual trust, and eventually in building sound relationships between IT and its end user environment, and as such in creating alignment between IT and the business. According to Moad (1994), the IT professional has been fighting for recognition and relevance at the CEO level for the last twenty-five years. He gives many examples illustrating the kind of culture that exists, which could be described as the main reason for misunderstandings and misconceptions about IT amongst today's end users.

When a user initially gets involved with the IT department, he/she is introduced to one or more IT professional(s) who will specifically deal with his/her problem(s). Normally a sense of mutual understanding and trust grows out of this relationship, which will definitely get disturbed the moment elements of such a relationship change without the knowledge or approval of the role players. In practice end users very seldom get involved in the management of change which will influence a relationship in which they are involved, or even get properly informed of changes that take place on the IT side. Practice has indicated that this is a typical reason for distrust and criticism against IT departments from the end user environment.

A review of literature on the history of relations between end users and their IT departments in the data processing industry and how they were treated, tells a very sad tale. The attitude or behaviour of IT departments or the so-called DP professionals was one of "we know the best", or "we know what the end user needs and therefore we don't need to try and get the end user involved". Furthermore, many people on the business-side of an organization have never been exposed to computer technology and are totally computer illiterate, which makes them uncertain and in many cases the "prey" of an IT department. As a result of this attitude few attempts were made to keep communication with the end user on a sound basis while developing a system.

Although many efforts were made in the past to address these issues, the emphasis mainly fell on putting structures and procedures together in order to get out of the end user what his basic needs are. Thereafter the IT department normally followed a lonely journey through the last phases of the systems development life cycle.

In the rest of the paper the nature of and theory behind ITend user relationships, and as such the way in which cooperation between IT professionals and end users take place, are examined. 


\section{The Nature And Theory Of It-End User Relationships}

The previous paragraphs briefly describe the history of how poor relationships emerged over the years between IT departments and their end users, as well as some basic characteristics of such poor relationships. The question one can ask is, what are the characteristics of sound relationships between IT departments and their end users, and how are they established. In other words, how can cooperation take place on a sound basis between IT professionals and end users. To answer the question, this section:

- gives a definition of IT-end user relationships,

- discusses the theory behind IT end user relationships, and

- explains what is meant by sound relationships.

\section{Definition of IT-end user relationships}

According to Leonard (1998) a relationship between an IT department and its end users consists of two dimensions, namely a physical dimension and an abstract dimension. The physical dimension describes those elements That are necessary in order to enable contact between IT and its end users, whereas the abstract dimension describes the soft issues of a relationship. These two dimensions enable one to fully describe the holistic nature of such a relationship and encapsulate the important elements of a support-oriented organization, namely mutuality, belonging, and connection, as mentioned by Pheysey (1993) in her book Organizational Cultures. (Under the description of the abstract elements the term 'holistic' is described in broader terms.)

Without going into all the detail of the different elements of the physical and abstract dimensions as described by Leonard (1998), the paper focuses on describing the most important characteristics of these elements. This will give the reader enough understanding of the social nature of ITend user relationships.

\section{Physical elements}

As far as the physical dimension is concerned, the following elements could be seen as the most important:

- People: A relationship consists of all the responsible people who are involved in the systems development life cycle at a given time. "Responsibilities are negotiated and shared between systems developers and users" (Dahlbom \& Mathiassen, 1993). (As human beings, people are viewed in this regard as the physical en- ablers who initiate, create, participate and maintain relationships, because of their interaction with one another during transacting. This is in line with the adaptive structuration theory of DeSanctis \& Poole (1994). See also Orlikowski (1992).)

- Technology: Technology may be seen as one of the most important elements in such a relationship, enabling the people who participate in the relationship to communicate with one another. The importance of proper communication structures, both vertically and horizontally, are emphasized by Bommer et al. (1991) and could be seen as one of the most important organizational characteristics associated with unethical activity. Apart from the normal communication technology, facilities like help desks and Internet are of the most important factors in this regard.

- Procedures: Two types of procedures are of importance, namely organizational procedures (such as standards and policies) which already exist and which can be seen as a given, and new procedures that are being created by people because of their interaction with the given procedures and technology (DeSanctis \& Poole, 1994).

- Structures: Depending upon the "type" of end user, and therefore the service and support that will be offered, relationships will differ in content as far as formal and informal social communication structures are concerned. The most common of these structures are project meetings, JAD sessions and end user group meetings.

An interesting example of a typical "physical" structure is the "team room". According to Sawyer et al (1997) the success of the facility lies in the fact the it "grew out of the software developers' own efforts to help themselves to work together."

\section{Abstract elements}

As far as the abstract dimension is concerned, the following elements are the most important:

- They are dynamic: The nature of the relationships between the IT department and its end users will, inter alia, depend upon the type of end user, as well as upon regarding the end user as a human being. According to Stokes (1991), when talking to end users, the IT professional should always bear in mind their concerns, problems, environment, and responsibilities in terms of opportunities for IT services and support. Furthermore, 


\section{Physical and Abstract Elements}

he says, continuous contact with end users gives IT the opportunity to gain more insight into their problems.

- They are sensitive to change: Because of the social nature of relationships, any form of change initiated on either the IT or the end user side may disturb a relationship. It is argued that any kind of change having an effect on any of the elements of both the physical and abstract dimensions of a relationship will in fact disturb the relationship because of its holistic nature, which will be described later.

- They have a knowledge base: The complex world of perceptions, attitudes and approaches towards developing software products by IT professionals for the end user, forces us to a point where it can be said that in order to overcome the most serious problems during this communication process in a relationship, a knowledge base of some kind is required before entering a relationship.

- They have a supportive culture: In order for a relationship to be sound, continuous support and mutual understanding, inter alia, need to be elements of such a relationship. According to Pheysey, a support-oriented organization has the elements of mutuality, belonging, and connection. Furthermore, an appreciative form of control should be applied, which means: "management is seen to be a process focused on maintaining balance in a field of relationships" (Gadalla and Cooper (1978), quoted by Pheysey).

- A co-operative behaviour pattern is followed by the participants: Co-operation is not a fixed pattern of behaviour, but a changing, adaptive process directed to future results. The representation and understanding of intent by every party is therefore essential to cooperation, and as such emphasizes the importance of communication during co-operation (Clarke \& Smyth, 1993).

Co-operation can also create new motives, attitudes, values and capabilities in the co-operating parties, which will help create and maintain a supportive culture. In other words, cooperation can only become a reality if the necessary social structures are in place. Social structure can be norms, values, roles and ways of interacting. This in turn can have an impact on the way in which physical structures are used. Furthermore, this can be seen as adaptive from a structurational perspective (DeSanctis and Poole, 1994).
- They have an holistic nature: The important elements making up a relationship between the IT department and its end users at a given time should be organized together as a whole. If any of these elements are disturbed in a negative sense, the whole relationship between the IT department and its end users is undermined. In other words, the relationship as a whole is more than the sum of its elements and therefore one can say that it has an holistic nature.

- Sustainability: A most obvious characteristic of the abstract dimension is its sustainability over a period of time. In this regard time refers to the life span of an ITend user relationship. One can therefore argue that out of an information systems viewpoint, a relationship of this kind will only last until the product or service reaches the end of its life cycle.

In this regard Introna (1994) states: "Structures as relationships are contingent, it appears and disappears. It could be brief (a few seconds) or long lasting (several years)."

- Commitment: Kinlaw (1989) states that one of the primary tasks of a manager is to create commitment and focus in employees. He furthermore states that managers who help employees increase their knowledge; skill and experience also are building employee commitment.

In this regard it is important that managers should take note of the four sturdy supports of commitment, namely: (a) clarity of goals and values; (b) employee competencies that ensure success; (c) the degree of influence that employees have; and (d) the expressed appreciation given to employees for their contributions. Commitment should be seen as a solid block that rests on these four sturdy supports or legs (Kinlaw, 1989).

Commitment has been defined by Newman \& Sabherwal (1996, referring to the work of Staw, 1982) as a state of mind that holds people and organizations in the line of behaviour. It encompasses psychological forces that bind an individual to an action. Commitment has been argued to greatly affect the persistence of behaviour (Newman \& Sabherwal (1996, referring to the work of Salancik, 1977).

All the elements described above form important subdimensions of the physical and abstract dimensions. Each of these elements plays a specific social role in an IT-end user relationship environment, which impacts on the 
soundness of a relationship and as such on the level of cooperation between team members.

\section{The theory behind IT-end user relationships}

At this stage it is necessary to ask: what is behind the construction of IT-end user relationships? In other words, what happens between the IT department and end users that is actually responsible for the establishment and maintenance of such relationships?

Although the record of service and support of IT departments was sketched as a very poor picture, interaction between the IT departments and their end users took place on a continued basis, because of the need to computerise different kinds of business systems. Over the years this ensured that relations between these two environments were established, in the sense that business people became more involved in computer projects, and consequently more computer literate. On the other hand, computer people were forced by the nature of many "computerization" projects to learn the business environment, and therefore developed a better understanding of business needs.

According to Introna (1994, referring to the work of Giddens, 1984), the structure of social systems emerges from interaction. Interaction establishes relationships. Structure is a set of relationships: communicative relationships, power relationships, etc. Structure as relationship is contingent, it appears and disappears. It could be brief (a few seconds) or long lasting (several years).

This is not only true of the structure, but also of the actors. As they redefine the structure (through interaction) they themselves get redefined. This implies that social structures (and the actors) not only emerge once, but are in a continual state of "becoming". This becoming flows from a pattern of interaction. It is an unfolding drama with no predefined script. This dramatical "human history" is created by intentional activities, but is not an intended project; it is persistently eluding efforts to bring it under conscious direction.

The process of becoming, of creation and recreation of structure is what Giddens (1984, p.25) calls the duality of structure.

Thus, society is truly historical. Social systems emerge from a pattern of interaction over time. They are shaped by it, and shape it. Any attempt to dismember an act or

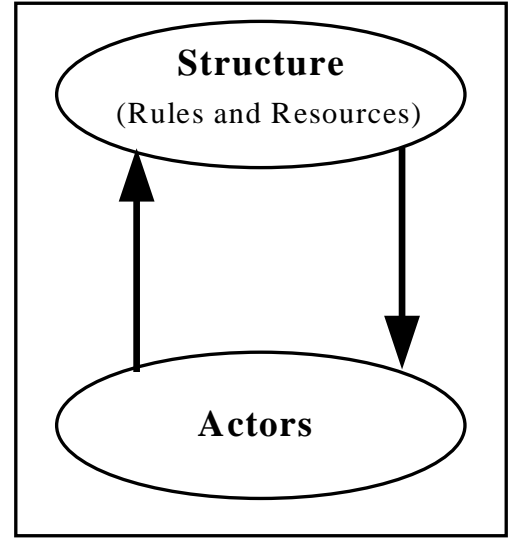

Figure 1: The structuration process (Based on Giddens (1984))

pattern of actions (relationship) from its historical context would be to do violence to the very being of self and society (see figure 1).

In the marketing research area much research has been done in the field of relations between manufacturers and customers. In this regard Pitt \& Bromfield (1994) state that managers interact in a number of so-called dyads in their everyday work. They define a dyad as: “...the smallest relationship unit, involving a one-on-one relationship between two parties."

This definition also relates to the idea of "user involvement transactions" introduced by Roode \& Smith (1989). It follows that in the case of a project team consisting of IT professionals and end users, a number of dyads (sub relationships) exist between the different individuals in such a team. Therefore, when transacting takes place whereby information between two or more parties is exchanged in

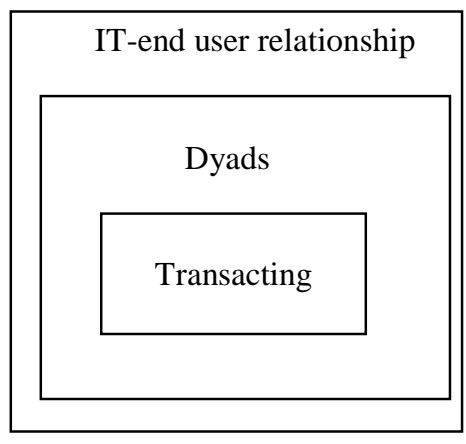

Figure 2: The building blocks of an IT-end user relationship 


\section{Physical and Abstract Elements}

order to determine for example the nature of the service requested by the end user(s), dyads are formed between the parties, but especially between IT professionals and end users.

The different dyads form the building blocks of an IT-end user relationship that emerges from the initial contact or transaction (exchange) made between an end user and an IT professional. Although transactions are regarded by Ciborra (1993) as the basic organizational relationship in which conflict of interest may take place, it is argued that transacting takes place before a dyad is formed. In this regard Ciborra himself states that one of the major purposes of a transaction, or exchange, is to search for a potential partner. This is illustrated in figure 2 .

IT-end user relationships could therefore be seen as social structures emerging when an IT professional and an end user starts to negotiate or communicate the elements (contents) of a specific service/support activity. In this regard Ciborra (1993) argues that some of the purposes of transacting is to signal willingness to exchange information, to establish the terms of the contract, and to serve as a base for maintaining communication during bargaining. It was also pointed out that the social process of transacting forms the basis from which dyads and eventually IT-end user relationships emerge.
The environment in which this takes place is provided by the IT department (institution) as a basis for IT-professionals and end users to perform planning, design, implementing and training, etc. "Social structures serve as templates for planning and accomplishing tasks" (DeSanctis \& Poole).

The most important advanced structures used by an emerging relationship, are composed of the physical and abstract dimensions thereof. In other words, an infrastructure (physical environment) has to be used by the actors (participants) of an emerging relationship to interact, and a knowledge base of the elements of the abstract dimension is required to direct behaviour. The construction of an emerging relationship is illustrated in figure 3 .

\section{The meaning of sound IT-end user relationships}

So far the term soundness has been used in order to indicate "that everything goes well with a relationship". This is actually a rather abstract term, which is very difficult to measure. In real life situations, for example, when one asks a project team member how things are with the team (meaning the team spirit), the typical response to such a question is "fine thank you". For any outsider, like a manager or any other person who does not belong to the team (and is therefore not involved in the relationship), it is even more difficult to give an objective answer. This type of

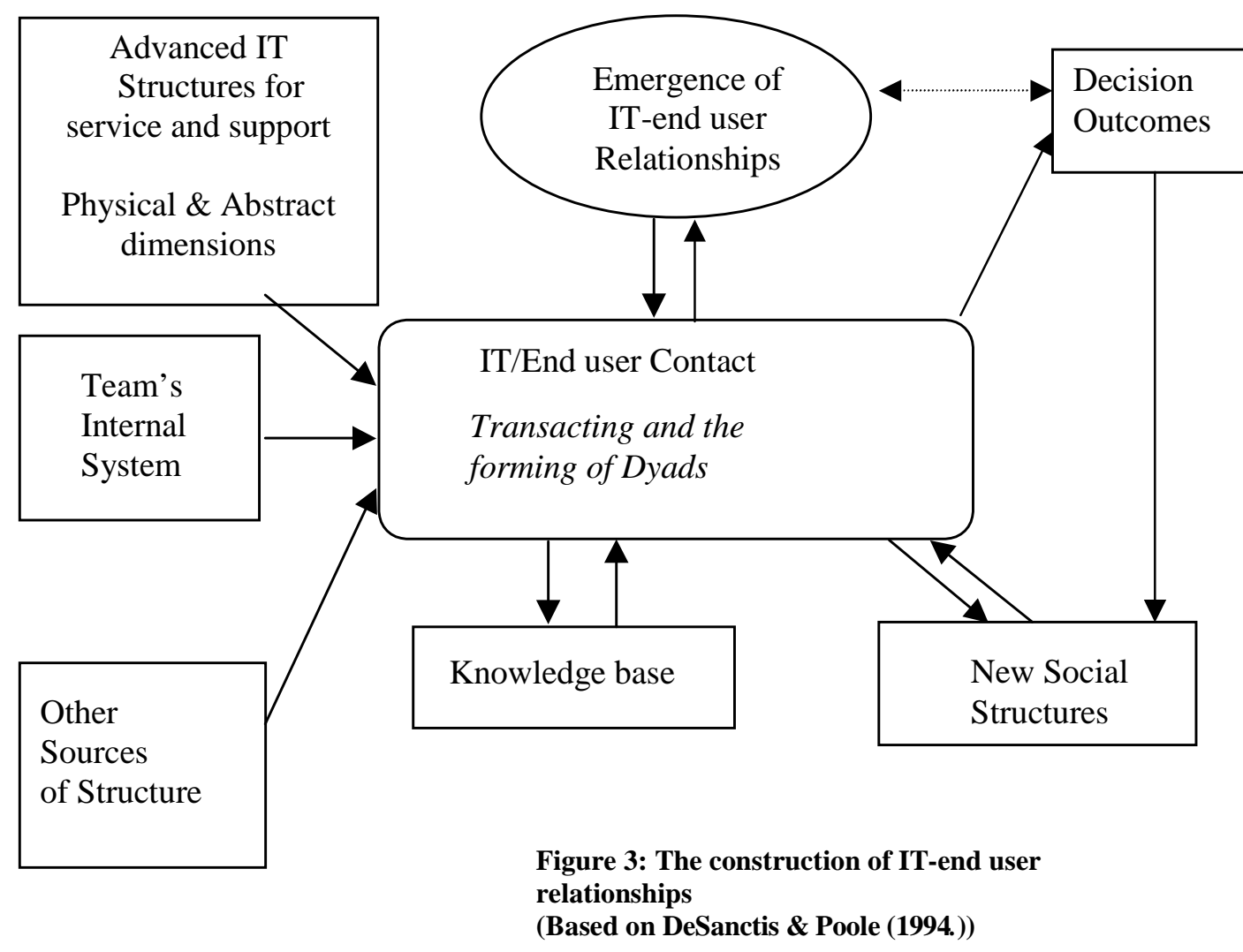




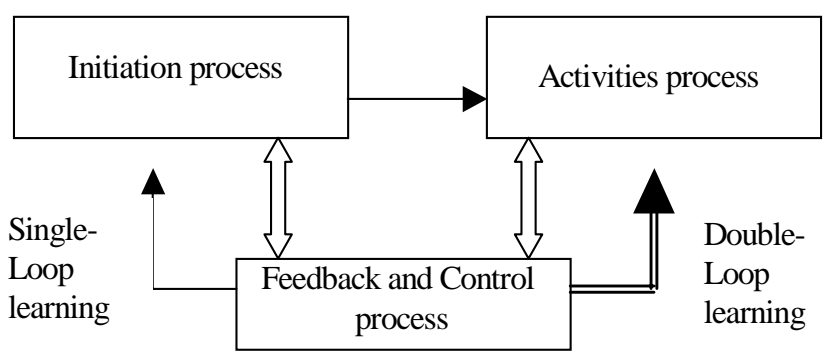

Figure 4: A summarized conceptual framework for IT-end user relationships

question, as well as the response to it, is normally quite subjective. One reason for this is because people play politics in the sense that they do not want to portray the situation as it really is - especially when things are not going that well. According to Agyris (1990) politics are in many cases the reason for the existence of "undiscussables", preventing people to talk about things that really matter. Pitt \& Bromfield (1994) state that political clout, rather than merit, can dictate the final decisions that may have a negative or destructive influence on the soundness of a relationship.

One of the important elements which plays a prominent role in the continuity of a relationship, and which also has a direct influence on the soundness thereof, is trust (Anderson \& Weitz, 1989; Humphrey, 1990). Many elements, like the "end user type" (in other words, whether the right end user is involved in the relationship) the "culture", communication etc. have an influence on the soundness of relationships, and therefore form determinants of trust in a relationship. In other words, these elements may be described as those that help to establish trust or mistrust in a relationship. Anderson $\&$ Weitz state that elements like reputation, support, cultural similarity and power imbalance are important determinants in building mutual trust levels in a dyad, and therefore in a relationship.

In the next section a conceptual framework is discussed by means of which sound relationships are established and maintained.

\section{A Conceptual Framework For It-End User Relationships}

The conceptual framework of IT-end user relationships consists of the following three main components, each of which has sub-components explaining the internal operations of each process (Leonard, 1998):

- relationship initiation process

- relationship activities process

- Feedback and control process.

The summarized conceptual framework is given in figure 4.

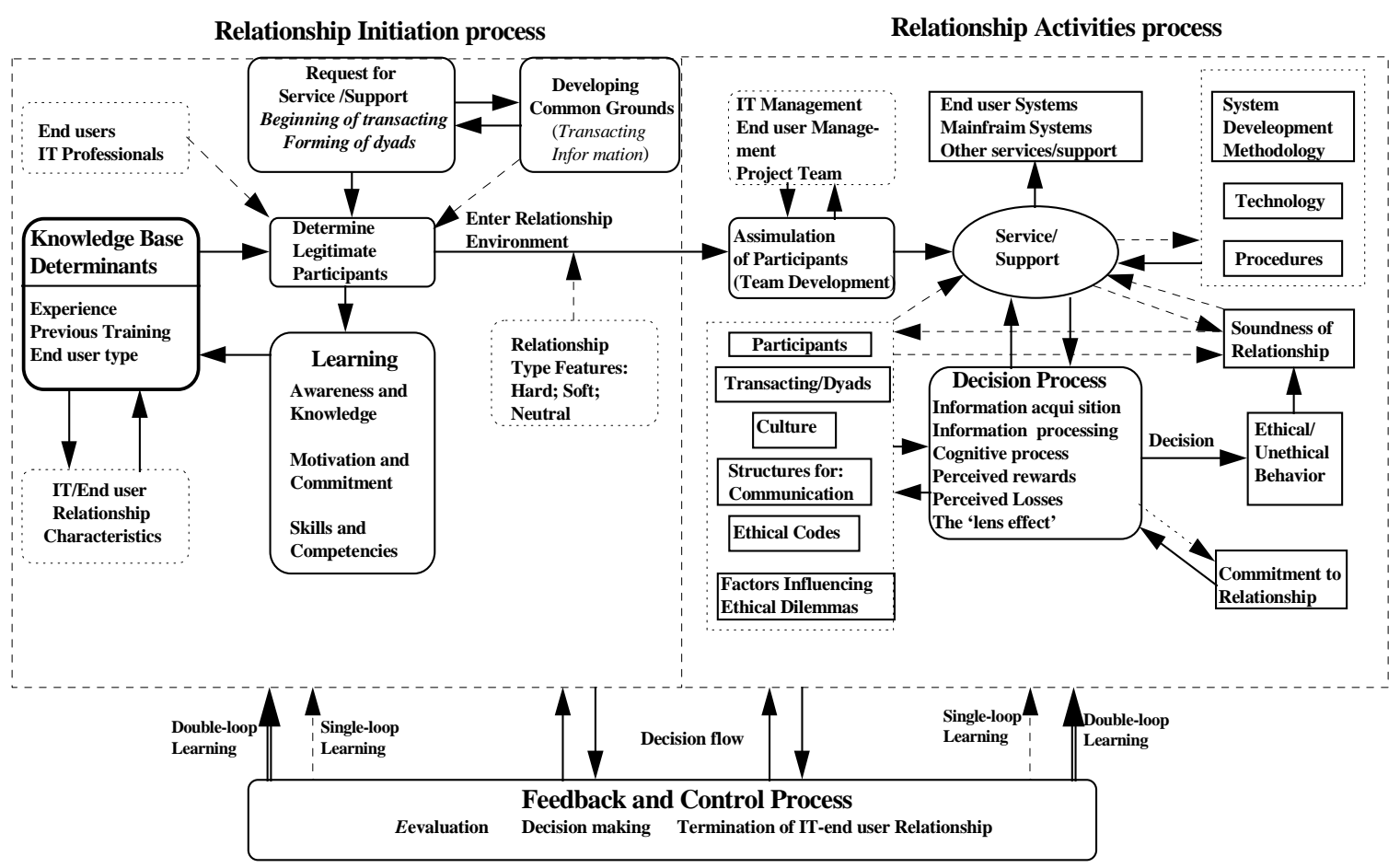

Figure 5: Conceptual framework of IT-end user relationships 


\section{Physical and Abstract Elements}

The conceptual framework with all the detail is illustrated in figure 5. These components present the life cycle of an ITend user relationship. Furthermore, although each component has a variety of elements (sub-components), which play a role during the life cycle of a relationship, the extent to which each element is involved depends on the type of relationship of which the discussion falls beyond the scope of this paper.

A brief description of each process is given below.

\section{- relationship initialization process}

The initiation process should be seen as the process taking place when the end user and the IT department start negotiating the terms and means of supplying a specific service or support to the organization.

\section{- relationship activities process}

During this phase of the relationship three major activities take place, which impact on or which are affected by the different elements in the physical and abstract dimensions. These activities are: assimilation of participants, service and support (for example, designing a system or maintaining an existing system), and the decision making process.

\section{- feedback and control process}

This is a continuous process affording all participants the opportunity to give their own evaluation (feedback) of how they experience the activities of a specific relationship in which they are involved. "Individuals learn as a result of their experience, and so do organizations.” (Robey \& Sales, 1994).

Furthermore, it allows participants to have control over the progress of a specific service and support activity (project).

\section{Conclusion}

In this paper the relationship between team members of a software project was defined in terms of its physical and abstract dimensions. It was argued that these two dimensions enable one to fully describe the holistic nature of such relationships. Furthermore, in terms cooperation between team members, it was argued that sound relationships would encourage cooperation between team members because the elements of both the physical and abstract dimensions will be of a sound nature.
The factors that impact on the soundness of relationships were discussed. It was pointed out that because of the holistic nature of these relationships, any of these elements, which may be in a "poor" state, might affect the soundness or sustainability of the relationship as a whole, and as such have a negative impact on cooperation between team members.

\section{References}

1997. "Relationship Matter", CIO (August).

Badaway K Michael, Electronic Business Buyer, Getting the most from cross-functional team, August 1994, Vol. 20 No. 8, 65-69.

Beard Jon W, Peterson Tim O, A Taxonomy for the Study of Human Factors in Management Information Systems (MIS). In Carey M J. 1988: Human factors in management information systems, Ablex Publishing Corporation, USA.

Boar, Bernard, H. 1994: Practical steps for aligning INFORMATION TECHNOLOGY with BUSINESS STRATEGIES: How to achieve a competitive advantage. John Wiley \& Sons, Inc. New York.

Bommer Michael, Gratto Clarence, Gravander Jerry, Tuttle Mark, A Behaviour Model of Ethical and Unethical Decision Making. In Dejoie Roy, Fowler George, Paradice David, 1991: Ethical Issues in Information Systems. Boyd \& fraser publishing company.

Brierley, Harold M, The Art Of Relationship Management. Direct Marketing, May 1994, 25-26.

Brown Antony, The view from the 21st century, Management today, December 1994, 5.

Caperelli David, Management Corner: Leading the company through the chokepoints of change, Information Strategy: The Executive's Journal, Spring 1996, 36-44.

Ciborra, Claudio U (1993): Teams, markets and systems Business Innovation and Information Technology, Cambridge University Press, UK.

Ciborra, Claudio U (1996) : Improvisation and Information Technology in Organizations. Proceedings of the Seventeenth International Conference on Information Systems, Cleveland, Ohio, December 16-18, 1996, 369-380.

Clarke, A A \& Smyth, M G G, A co-operative computer based on the principles of human co-operation: International Journal of Manmachine studies, Vol. 38, 1993, 3-22.

CSC Foundation, 1994: Future roles and responsibilities for the IS Department, Final Report 96.

Dahlbom B, Mathiassen L, 1993: Computers In Context; The philosophy and Practice of Systems Design. Blackwell Publishers, Cambridge UK. 
De Jarnett, Larry R, Focusing the IS organization (Or, what's with clients and customers), Information Strategy: The Executive's Journal, Fall 1993, 3-4.

DeSanctis, Poole M S, Capturing the Complexity in Advanced Technology Use: Adaptive Structuration Theory, vol 5, No. 2, May 1994.

Di Carlo, Paul, Information systems management, Telecommunications, March 1989, 49-58.

Du Plooy NF, The social aspects of Information systems, Working paper series, University of Pretoria, July 1993.

Du Plooy NF, Overcoming the culture gap between management and IT staff, Paper delivered at Conference on "HR Management of IT staff', IEC, Jan Smuts, March 1995.

Giddens, A. 1984: The Constitution of Society. Berkeley, University of California Press.

Henderson JC \& Venkatraman N. 1992. Strategic Alignment: A Model for Organizational Transformation Through Information Technology. In Transforming Organizations. Kochan TA, Useem M. Oxford University Press. New York.

Introna Lucas D, 1994: Giddens, Emergence and Social Intervention. Paper presented at the International Conference on Systems Thinking and Progressive Social Change, University of Cape Town, South Africa, 2-15.

Introna L D, Whitley EA, Imagine: Thought Experiments in Information Systems Research. Proceedings of the IFIP TC8 WG 8.2International Conference on Information Systems and Qualitative Research, Philadelphia, Pennsylvania, USA. 31 st May $-3^{\text {rd }}$ June 1997, 481-496.

Jackson, Ivan F., 1986: Corporate Information Management, PrenticeHall, London.

Kavanagh Donncha, Araujo Luis, Chronigami: Folding and Unfolding Time, Accounting, Management and Information Technology, 1995, Vol. 5, No. 2, 103-121.

Kelly, Mark, 1991: The Adventures of a Self-Managing Team, Pfeiffer \& Company, San Diego.

Kinlaw, Dennis C., 1989: Coaching for Commitment: Managerial Strategies for Obtaining Superior Performance, University Associates, Inc.,USA

Klein, HK \& Myers, MD. 1996: The evaluation of interpretive research in Information Systems. Manuscript submitted for publication.

Leonard AC, 1998: Information Technology-End User Relationship In A Changing Environment, Thesis (D.Com.(Informatics))University of Pretoria,1998. Unpublished.

Luevano, Fred Jnr, MIS's role in service-level agreements. In Umbaugh R E, 1991: Handbook of IS Management (Third Edition), Auerbach Publishers, Boston and New York, 1991, 125-134.
Moad Jeff, Does your CEO get it?, Datamation, September 1994.

Morris Ted, Customer relationship management, CMA Magazine, Vol 68, Part 7, September 1994, 22-25.

Newman Michael \& Sabherwal Rajiv (1996): Determinants of Commitment to Information Systems Development: A Longitudinal Investigation, MIS Quarterly, March 1996, 23-54.

Orlikowski WJ, The duality of technology: Rethinking the concept of technology in organizations, Organizational Science, August 1992, $399-427$.

Papp, Raymond, Alignment of Business and Information Technology Strategy: How and Why? 2000.

Pheysey, Diana C, 1993: Organizational Cultures, Routledge, New York.

Pitt, Leyland F \& Bromfield, Derek, 2nd ed 1994: The marketing decision maker: From MkIS to MDSS, Juta, Kenwyn.

Reich, B,H, Benbasit, Izak. 1999: Factors that influence the social dimension of alignment between business and information technology objectives. By the Society of Information Management (SIM) and the Management Information Systems Research Center (MISRC).

Richards-carpenter, Colin, Senior managers must learn how to love their computers, People Management, 9 February 1995, 47.

Roode J D, A J Smith, User involvement in systems development: South African Journal of Economic and Management Sciences, Vol. 2, November 1989, 7-20

Sahay S, Palit M \& Robey D, A relativist approach to studying the social construction of information technology: European Journal of Information Systems, Vol. 3 No. 4, 1994, 248-258.

Sawyer Steve, Farber Joel \& Spillers Robert, Supporting the social processes of software development: Information Technology and People, Vol. 10 No. 1, 1997, 46-62.

Sprague, Ralph H \& McNurlin, Barbara C, 3rd ed 1993: Information systems management in practice, Prentice Hall, Englewood Cliffs.

Stokes, Stewart L (Jr), A Marketing Orientation for End-User Computing Support. In Umbaugh R E, 1991: Handbook of IS Management (Third Edition), Auerbach Publishers, Boston and New York, 125-134.

Tapscott Don, Caston Art, 1993: Paradigm Shift: The New Promise of Information Technology, McGrawhill Inc., New York.

Umbaugh R E, 1991: Handbook of IS Management (Third Edition), Auerbach Publishers, Boston and New York.

Wike W R, Andersen A \& Co., Service management. CMG XV International conference on the management and performance of computer systems: Conference proceedings, p. 534-540, December 1984, San Francisco, USA. 